\title{
Dehumidification Analysis of Rotary Solid Desiccant Wheel \& Packed Bed System
}

\author{
D.O.I - 10.51201/Jusst12670 \\ http://doi.org/10.51201/Jusst12670
Taliv Hussain*, Zafar Alam, Danish Ahamad, Md Salik Anwar, Sadique Istekhar Ahmed and Adnan Hafiz

Mechanical Engineering Department, Aligarh Muslim University, Aligarh, India. 202002

\begin{abstract}
Moisture transport is one of the major challenges in desiccant dehumidification. The transfer of moisture basically involves transfer of heat between moist air and desiccant particles as well as the mass transferal of moisture between moist air and desiccant particles. Type of desiccant dehumidification analysis is heating with dehumidification. Warmth move between sodden air and desiccants likewise gains consideration since temperature appropriation significantly influences the mass exchange execution through desiccant isotherms. The warmth and mass exchange between a clammy air stream and desiccant particles is dissected. Surface dissemination is noticed to overwhelm mass exchange within the silica gel particles. Here in this paper, we have compared the three diffusion coefficients Ordinary, Knudson and surface diffusion both for packed bed system and rotary desiccant system. Also, two models of move coefficients are introduced here and analyzed. Pseudo gas side controlled model usages an observational gas side mass exchange coefficient to represent dissemination opposition on strong side. Solid side resistance model settles the dissemination condition and is the finest exact as far as move coefficients. Notwithstanding, it makes examination considerably more clear.
\end{abstract} Keywords: Dehumidification, silica gel, diffusion, heating.

\section{INTRODUCTION}

Desiccants are a class of materials that upon interaction with sodden air at adequate temperatures show an extraordinary proclivity for water fume. In fact talking, almost any material be suitable as a desiccant - even glass can pull in limited quantities of water from the air. Nonetheless, desiccants utilized for space molding (Air molding) should have the option to hold a lot bigger measures of water. Business strong desiccant ingredients can grasp up to half of their weightiness 
in water. Silica gel, atomic sifter and initiated carbon are basic business strong desiccants [1]. Fluid desiccant can adsorb considerably additional dampness. Desiccants have been found to go about as a decent channel for pollutants, notwithstanding eliminating particulate foreign substances; desiccants consolidate fume toxins out of the air. Desiccants are viable in eliminating nitrogen dioxide, carbon monoxide and sulphur dioxide. Additionally, issues, similar to shape, brought about by utilizing water in regular frameworks don't happen in desiccant dehumidification. Along these lines, desiccant frameworks have a decent prospective to enhance indoor air quality [2]. Pesaran (1983) [3] took care of job on hypothetical and exploratory investigation of the silica gel stuffed molecule execution. A seat scale test rig was utilized to get information for boundary esteems relevant to sun powered cooling applications. Both desorption and adsorption tests were conducted for Regular Density (RD) silica gel for a wide scope of molecule size. Adsorption information were likewise acquired for Intermediate Density (ID) gel. A model of warmth and mass exchange in the bed was created with unique spotlight on paid to the displaying of strong side opposition. Both Surface and Knudsen dissemination are discovered to be significant systems of dampness transport instrument in Intermediate Density gels while surface dispersion is predominant in Regular Density gels. They fitted producers information for grade 01 and grade 59 silica gel, that have been for most part utilized in the desiccant dehumidification industry. A model is created to foresee the consistent intermittent presentation of an outspread stream desiccant wheel. The model is communicated as far as the very dimensionless boundaries that are regularly utilized in displaying of the customary hub stream desiccant wheel. An affectability study is done to examine the impact of altering slightly of these boundaries on exhibition of wheel. The exhibition of outspread stream desiccant wheel is contrasted and that of ordinary hub stream desiccant wheel having similar estimations of activity boundaries [4]. Abasi et.al (2016) [5] joins rotating desiccant wheel division into an air recycled convective dryer and analysis it through drying corn portions. Analysis were directed with and without desiccant wheel at air temperatures of 50,60 , and $70^{\circ} \mathrm{C}$ and stream paces of $1,1.4$, and $1.8 \mathrm{~kg} / \mathrm{min}$. Impact of drying temperature, energy utilization, wind current rate, desiccant wheel drying rate, drying time and explicit dampness extraction rate were researched. Results demonstrated that desiccant wheel is an efficient and helpful framework to use in dryers since it diminishes drying period but expanding the drying rate and impacts energy utilization. Dai et al. (2001) [6] introduced wave examination utilizing psychometric outline to assess the exhibition 
of turning desiccant. To enhance the exhibition of dehumidification as per wave shape were proposed and some significant boundaries for example heat limit, adsorption heat, revolution speed, desiccant isothermal shape, recovery temperature and thickness of desiccant network were examined in detail utilizing Psychrometric outline. The current plan of independent VCRs should be adjusted by coordinating it with strong desiccant based dehumidification framework to accomplish better execution and financial possibility by taking care of moistness and temperature independently particularly in the event of hot muggy conditions. By considering assortment of view points including foundation and requirement for elective cooling frameworks, framework setup just as operational techniques and current status of desiccant based half breed refrigerating innovation. Innovation of desiccant created mixture refrigerating has an incredible prospective to give warm solace particularly in sweltering muggy environment to the detriment of lower energy utilization when contrasted with conventional cooling frameworks [7]. Adding or eliminating warmth and dampness relies essentially upon the warmth and mass exchange qualities inside the framework. In this examination, the warmth and mass exchange attributes, as Nusselt number $(\mathrm{Nu})$ and Sherwood number (Sh) of honeycomb desiccant dehumidifier were explored tentatively. Honeycomb desiccant dehumidifier was driven by utilizing honeycomb desiccant design, that was built from polymer adsorbent substantial. Adsorption temperature was deliberated as a flexible boundary utilizing estimations of $20^{\circ} \mathrm{C}$, $25^{\circ} \mathrm{C}$ and $35^{\circ} \mathrm{C}$. Every adsorption temperature was assessed under time spans for desorption and adsorption measures (exchanging time: $\tau$ ) of 60:60 $\mathrm{min}, 60: 90 \mathrm{~min}, 60: 120 \mathrm{~min}$ and 90:120 $\mathrm{min}$. For given boundaries, desorption temperature and mass stream pace of air were retained unaltered at $55^{\circ} \mathrm{C}$ and $0.1 \mathrm{~kg} / \mathrm{s}$ separately. Outcomes presented that $\mathrm{Nu}$ and $\mathrm{Sh}$ are all the additional equally receptive to alteration of adsorption temperature than exchanging time. Less desorption temperature brings about large estimations of Sh and $\mathrm{Nu}$ [8]. Expanding coefficient of execution (COP) of fume pressure refrigeration frameworks by using regular air cooled condensers is necessary issue particularly in regions having antagonistic surrounding conditions. A powerful method of handling this issue is through an evaporatively cooled condenser. Impact of evaporative cooling on presentation of fume pressure refrigeration framework at three diverse encompassing temperatures of $23^{\circ} \mathrm{C}, 29^{\circ} \mathrm{C}$ and $35^{\circ} \mathrm{C}$ are examined. It likewise thinks about impact of cellulose and steel-wire network cushions utilized in an evaporative cooler. Impact on presentation of fume pressure refrigeration framework is additionally assessed by varying three 
distinctive wind stream rates (i.e., $1.15,0.93$ and $0.88 \mathrm{~m} / \mathrm{s}$ ) in air and evaporative cooled condensers. Exploratory outcomes display that at $23^{\circ} \mathrm{C}$ for wind stream pace of $0.88 \mathrm{~m} / \mathrm{s}$ the exhibition of the framework is expanded by $2.3 \%$ and $1.1 \%$ by utilizing an evaporative cooler utilizing cellulose and steel wire cushions, individually, when contrasted with air-cooled condenser [9].

Here in this research paper, we have compared the three diffusion coefficients Ordinary, Knudson and surface diffusion both for packed bed system and rotary desiccant system. Also, two models of move coefficients are introduced and analyzed. Pseudo gas side controlled model utilizes an observational gas side mass exchange coefficient to represent the dissemination opposition on strong side. Solid side resistance model settles dissemination condition and is the most exact as far as move coefficients.

\section{EXPERIMENTAL SETUP}

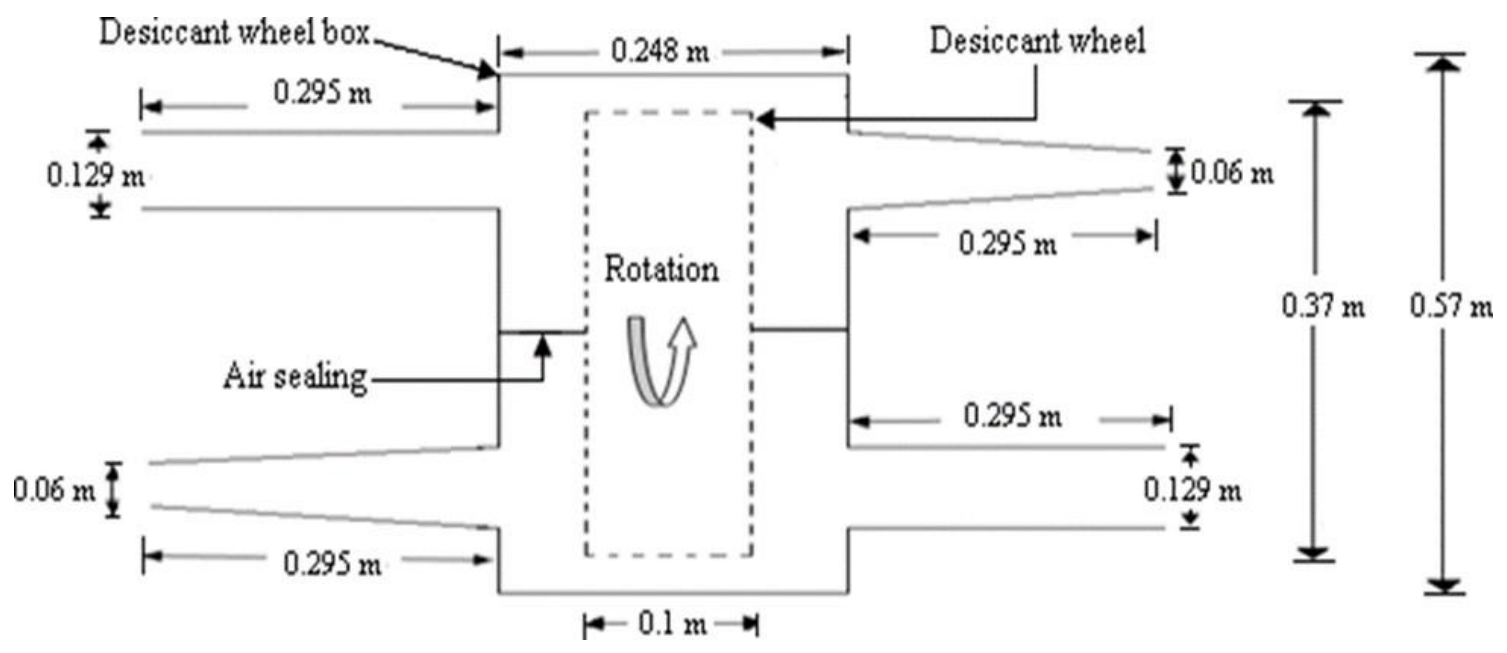

Figure 1 Schematic diagram of rotary desiccant wheel

Experiments have been performed on the rotary desiccant wheel by measuring dry bulb temperature and relative humidity with help of digital thermo hygrometer. A detailed schematic diagram of desiccant wheel is presented in figure 1. Line diagram of experimental setup is represented in figure 2 .

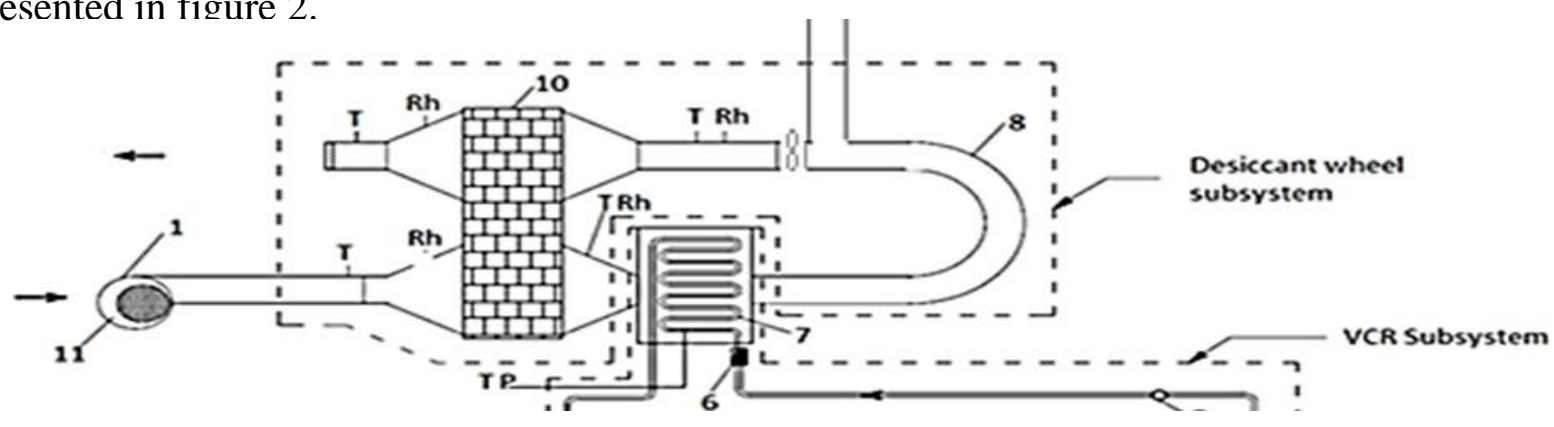


Figure 2 Line diagram of actual setup

\begin{tabular}{|l|l|l|l|}
\hline T- Temperature & 1) Blower & 5) Sight Glass & 9) Anemometer \\
\hline P- Pressure & 2) Compressor & 6) Expansion Valve & 10) Desiccant wheel \\
\hline $\begin{array}{l}\text { Rh- Relative } \\
\text { humidity }\end{array}$ & 3) Condenser & 7) Cooling Coil & $\begin{array}{l}\text { 11) Variable speed } \\
\text { derive }\end{array}$ \\
\hline F- Flow Rate & $\begin{array}{l}\text { 4)Refrigerant } \\
\text { Flow Meter }\end{array}$ & 8) Duct Connection & \multicolumn{2}{|}{} \\
\hline
\end{tabular}

\section{METHODOLOGY}

Precise exchange quantities are critical to a decent warmth and mass exchange model. Reviewing Biot number investigation, mass exchange opposition in silica gel particles rules and warmth move obstruction in strong stage assumes a part with large Reynolds numbers. As referenced previously, a thermally lumped molecule can be accepted for warmth move coefficient purposes without clear error. In any case, we actually need to manage the issue of displaying the strong side mass exchange, that is vital to foreseeing desiccant dehumidification exhibitions. In this segment, two models to report within mass exchange coefficients are talked about: Solid side resistance model and Pseudo gas side controlled model.

\section{Solid Side Resistance Model}

Diffusion in solid phase take over mass transference among air stream and desiccant particles. Here following second order partial differential equation shows diffusion method in solid particles is represented by equation 1 .

$$
\frac{\partial W_{d}}{\partial t}=\frac{1 \partial}{r \partial r}\left(D r^{\partial H_{d}}\right)
$$

Here,

$W_{d}=$ Water content in desiccant, $\mathrm{D}=$ Water Diffusivity within desiccant particles $\left(\mathrm{m}^{2}\right)$

$\mathrm{R}=$ Length scale in spherical coordinates $(\mathrm{m})$ and $\mathrm{t}=$ Time scale (s). 
In solid side resistance model, the above equation is resolved together with other system governing equations. Solving diffusion equation brings one more dimension and various new variables in examination and in calculation whereas normally getting improved outcomes. Neglecting internal heat transfer resistance is satisfactory for practical utilities. Thus, pure gas side convective heat transfer coefficient can be utilized as overall heat transfer coefficient in silica gel moist air system. On the basis of assessment of existing literature on mass transferal in packed particle beds, Pesaran utilizes following relations for gas side transfer coefficients. The heat transfer coefficient for Solid-side Resistance model is given by equation 2 [8].

$$
h=1.60 \dot{m}_{a i r} R_{e}^{-0.42} C_{p, e}
$$

\section{Pseudo gas side Controlled Model}

Addressing dispersion condition can be dodged if there is some experimental connection accessible for general mass exchange coefficient, as is done in warmth exchanger industry. Luckily, Hougen and Marshall suggested such connections for silica gel clammy air framework bed dependent on Ahlberg's examination [10]. Ahlberg acquired trial information for paces of water adsorption from air through silica gel stuffed molecule beds for different wind current rates and molecule sizes. A model is accepted wherein particles have a uniform dampness substance and temperature and general exchange interaction might be addressed by pseudo gas side exchange coefficients. By suitable model conditions, they noticed that Ahlberg's information might be recuperated utilizing accompanying connections for exchange coefficients [11].

$$
h_{e f f}=0.683 \dot{m}_{a i r} R e^{-0.51} C_{p, e}
$$

Here, $\dot{m}_{\text {air }}$ mass flow rate per unit area $\mathrm{kg} / \mathrm{m}^{2} \mathrm{~s}$ and $C_{p, e}$ specific heat of air $\mathrm{J} / \mathrm{kgK}$.

\section{Heat Transfer Biot Number}

Warmth move among desiccants and a sodden air stream incorporates conductive warmth move inside molecule (equation 4) and convective warmth move outside the molecule (equation 5). Regardless of whether the conductive obstruction can be overlooked relies upon its overall significance contrasted and the convective opposition. The warmth move Biot number is 
proportion of inner conductive protection from the outside convective obstruction addressed by equation 6.

Convective heat transfer resistance outside particle

$$
R_{\text {conv }}=\frac{1}{h_{c} A}
$$

Conductive heat transfer resistance inside particle

$$
R_{\text {cond }}=\frac{d_{D}}{k_{d} A}
$$

Here, $\boldsymbol{k}_{d}=$ Thermal conductivity of desiccant $(\mathrm{W} / \mathrm{mK}), \boldsymbol{h}=$ Gas side heat transfer coefficient $\left(\mathrm{W} / \mathrm{m}^{2} \mathrm{~K}\right)$ $\boldsymbol{A}=$ Heat transfer area $\left(m^{2}\right)$ and $d_{p}=$ Particle diameter $(\mathrm{m})$

$$
B_{i, h}=\frac{h_{c} d_{p}}{k_{d}}
$$

Mills gave heat transfer correlation for flow of gases in packed bed as following[12].

$N u=\left(0.5 \operatorname{Re}^{(1 / 2)}+0.2 \operatorname{Re}^{(2 / 3)} \operatorname{Pr}^{(1 / 3)}\right.$

$h_{c}=\frac{\left(\mathbb{N}, \frac{k_{\text {aij }}}{d_{p}}\right)}{p_{p}}$

$\operatorname{Pr}=0.69$, for air

Normal thickness Grade 01 silica gel is utilized in this work. Standard designing practice to totally overlook within conduction obstruction is $\mathrm{Bi},<0.1$. It can be noticed that warmth move Biot number is little and within heat conduction obstruction can be disregarded once air speed is less.Conduction obstruction can't be disregarded when within and outside protections draw nearer and Biot number goes beyond 0.1. In that situation, we actually can work on issue via accepting a thermally lumped molecule framework [12].

\section{Mass transfer mechanism}

\section{Diffusion coefficients}

Mass transfer within solid particle is difficult due to porous behavior of desiccants. Three different mechanisms of diffusion can happen in the porous solids as Ordinary diffusion, Knudsen diffusion and Surface diffusion [12]. For moisture adsorbed in regular density silica gel with precise less pores, it is necessary to estimate the extents of these diffusion mechanisms. 


\section{Diffusion coefficients of Packed bed Analysis}

(a) Ordinary diffusion coefficient

Ordinary diffusion happens when particles of gas interact with one another more regularly as that of with pore walls of a porous medium. For porous materials like silica gel, ordinary diffusion of moist air into desiccants in fact occurs between water vapour and air confined within pores. The ordinary diffusion coefficient is given by [13].

$$
D_{O}=1.735 \times 10^{-9} \times \frac{(T+273.15)^{1.685}}{P} \quad m^{2} s^{-1}
$$

Here, $\mathrm{P}$ is in atmospheres and $\mathrm{T}$ is gas temperature in degrees Celsius.

(b) Knudson diffusion coefficient

Knudsen diffusion, the gas molecules interact much repeatedly with pore walls than with each other and diffusion of molecules is defined by equations of free molecule flow. Fick's law type expression might be attained for this kind of flow if Knudsen diffusion coefficient $D_{k}$ is defined [13].

$$
D_{K}=22.86 a(T+273.15)^{0.5} m^{2} s^{-1}
$$

Here, $\mathrm{a}$ is radius of pore in meters and $\mathrm{T}$ is gas temperature in degree Celsius.

\section{(c) Surface diffusion}

Surface diffusion is transport of adsorbed molecules on pore surface. A number of potential mechanisms for movement of adsorbed molecules on surfaces were suggested.

Sladek et al. derived a simpler formula as follows [14].

$$
D_{S}=\frac{D_{a}}{\tau_{s}} \exp \exp \left(-0.974 \times 10^{-3} \times \frac{H_{a d s}}{T+273.15}\right) m^{2} s^{-1}
$$

Surface tortuosity factor, $\tau_{s}$ accounts for increment diffusion resistance in real pores matched with theoretically smooth surface. San used, $\tau_{s}=1.0$ to model cyclic processes in desiccant packed beds since it provide good matching between experiment and simulation [15].

\section{Diffusion coefficients of Rotary desiccant system}

(a) Ordinary diffusion coefficient

Ordinary diffusivity can be determined by Niu et al.[16]. 


$$
D_{0}=1.758 \times 10^{-4} \frac{T_{a}^{1.685}}{P_{a t m}}
$$

\section{(b) Knudson Diffusion}

Knudsen diffusion arises in desiccant pores; it depends upon pore diameter and cannot be ignored. Knudsen diffusion coefficient can be determined by Niu et al. [16].

$$
D_{K}=97 r\left(\frac{T_{a}}{M}\right)^{0.5}
$$

\section{(c) Surface Diffusion}

Surface diffusivity $\left(\mathrm{D}_{\mathrm{S}}\right)$ can be determined by following equation given in Niu et al. [16].

$$
D_{s}=\frac{1}{\zeta} \times 1.6 \times 10^{-6} e^{\left(-0.974 \times 10^{-3} \frac{q_{s t}}{\left.T_{a}\right)}\right.}
$$

Where $\zeta$ is tortuosity factor that account for increment in diffusion length due to tortuous path of real pores.

Adsorption heat of regular density silica gel as suggested by Ge et al. [17].

$$
q_{s t}=\left(2504.4-2.4425 T_{a}\right)\left(1.0+0.2834 e^{-10.28 W}\right)
$$

\section{RESULTS AND DISCUSSION}

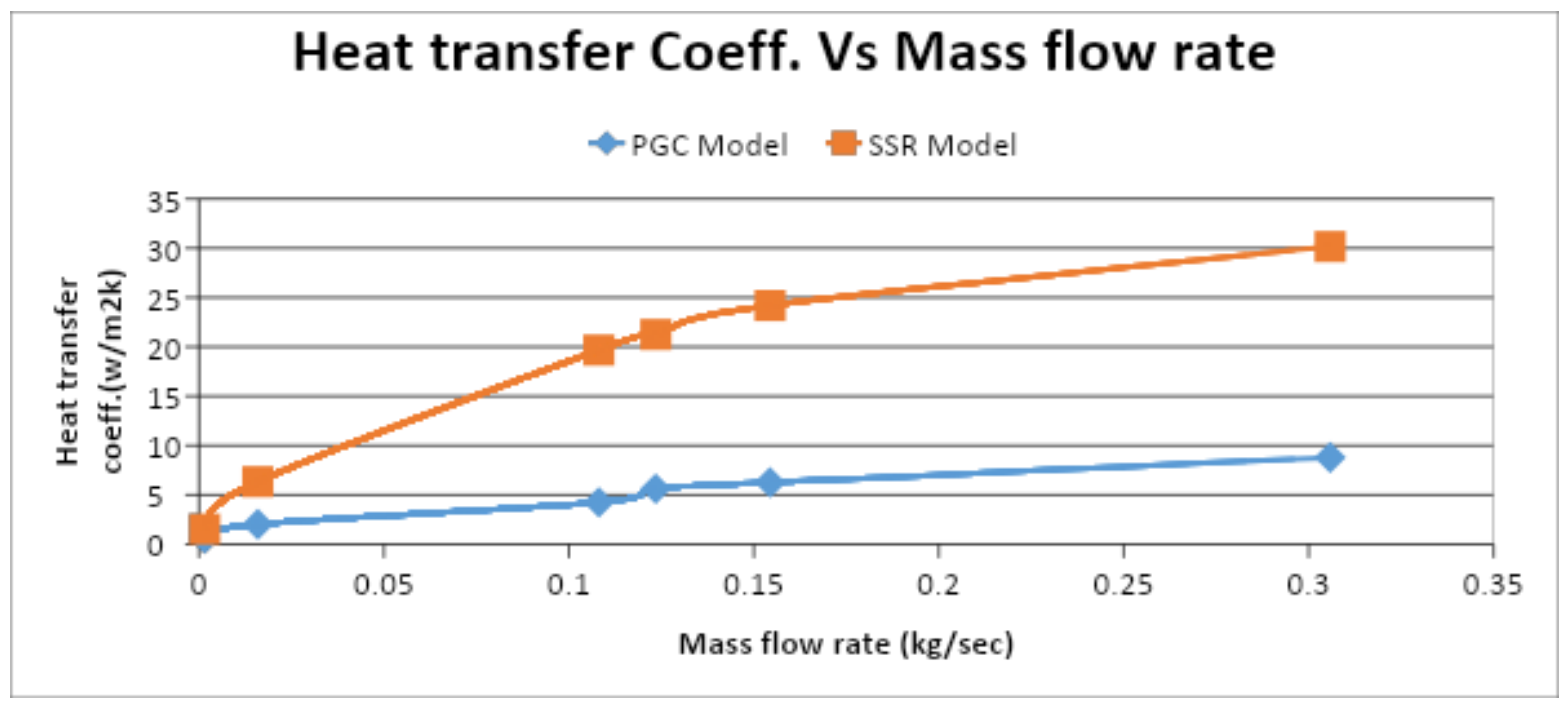

Figure 3 Variation of Heat Transfer Coefficient (h) with Mass flow rate.

From figure 3, it is clear that heat transfer coefficient increases with increment in mass flow rate. Also at same mass flow rate, $h_{\text {pseudogas }}<h_{\text {SSR, }}$. That is heat transfer coefficient for Pseudo Gas 
Controlled model is less as compared to heat Transfer coefficient of Solid Side Resistance model.

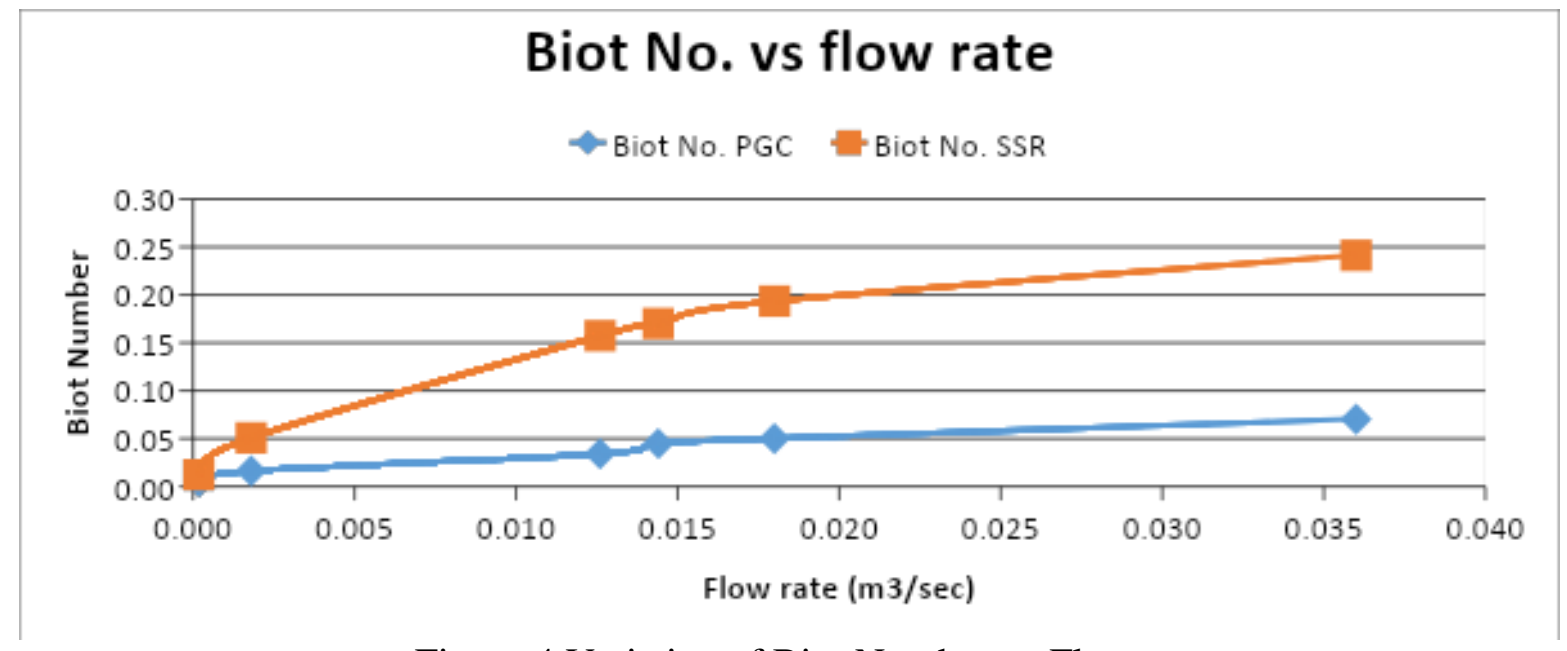

Figure 4 Variation of Biot Number vs Flow rate.

From the figure 4, it is found that as flow rate increases, Biot number also increases. Also, at the same flow rate, $B_{i(S S R)}>B_{i(P G C)}$. That means SSR model has less resistance to convective heat transfer as compared to PGC Model, which implies that there will be more transfer of heat in case of SSR.

Figure 5. Variation of Diffusion coefficient with Temperature of Air.

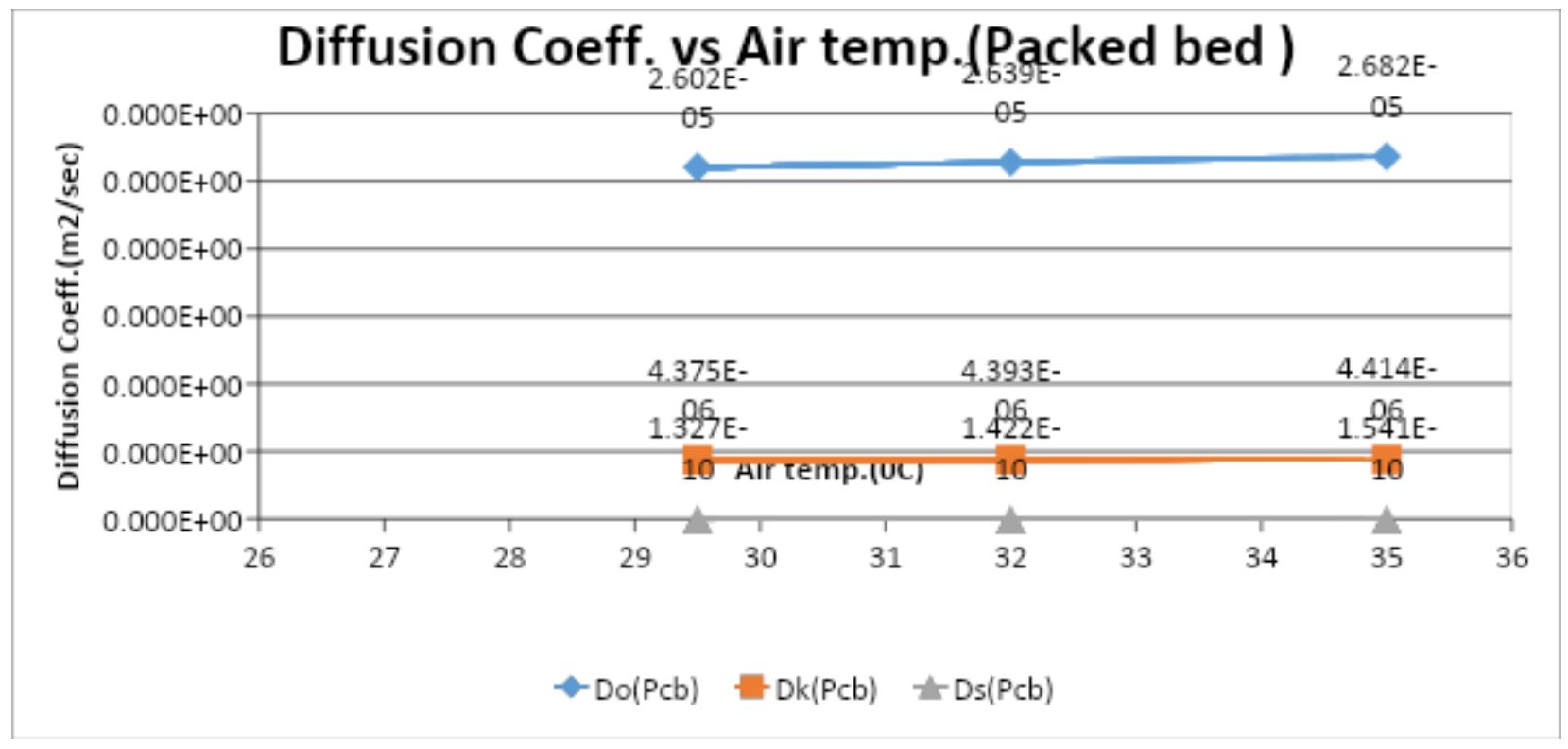


Figure 5. shows that all the three Diffusion coefficients (Ordinary Diffusion, Knudson diffusion\& Surface diffusion) for packed bed Desiccant system show a very steep increment with temperature, though they are increasing with temperature. Also, at the same Temperature of air, $\mathrm{D}_{\text {Surface }}<\mathrm{D}_{\text {Knudson }}<\mathrm{D}_{\text {Ordinary }}$, Diffusion coefficient (D) basically is analogous of heat transfer resistance in mass transfer. Amongst the all three diffusion coefficients, Surface diffusion coefficient is found to be minimum, nearly touching the abscissa, which shows that Surface diffusion mechanism dominates mass transfer inside silica gel particle.

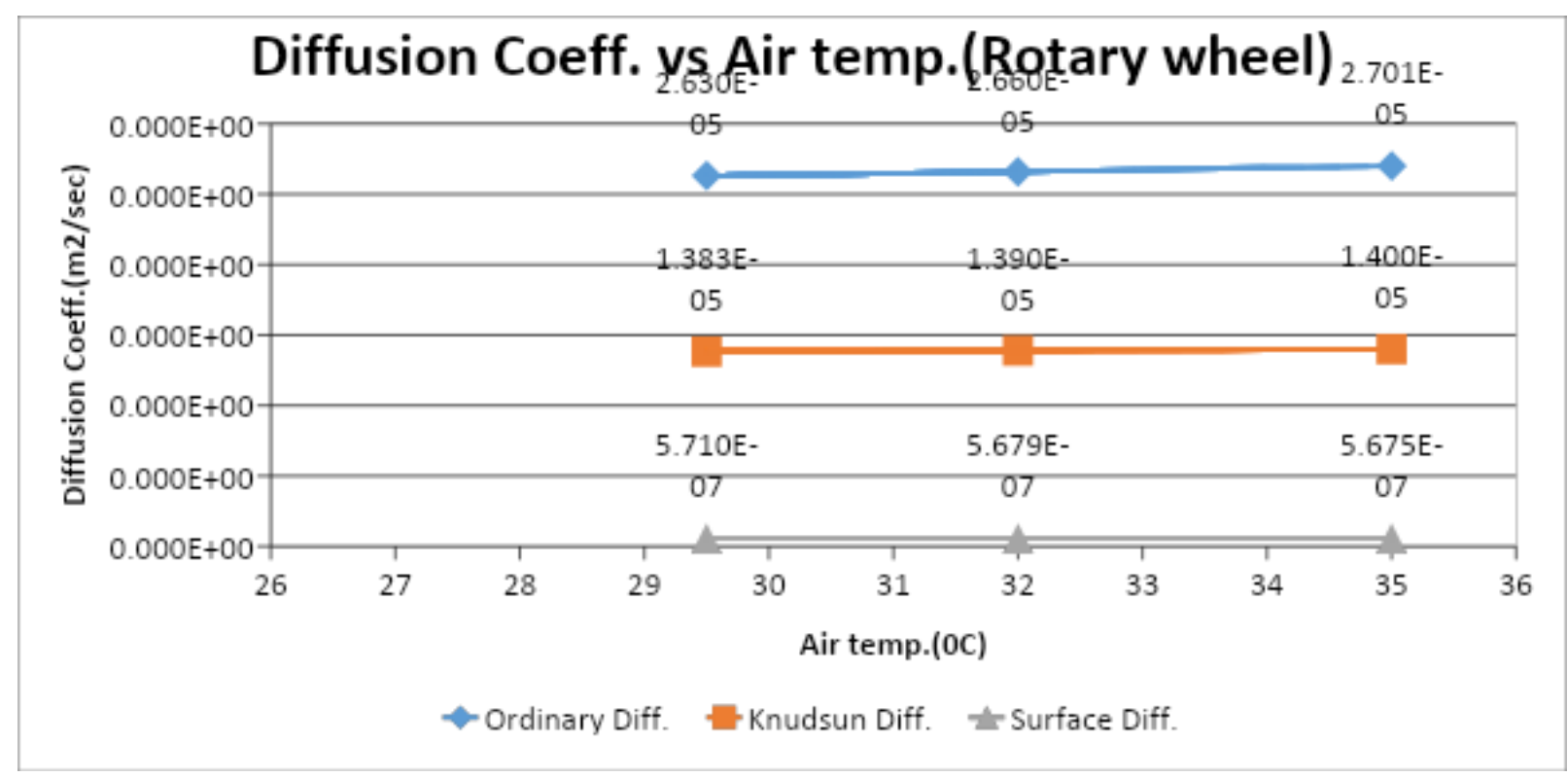

Figure 6. Variation of Diffusion Coefficient with Temperature of Air

Figure 6. shows that all the three Diffusion coefficients (Ordinary Diffusion ,Knudson diffusion\& Surface diffusion) for Rotary Desiccant wheel show a very steep increment with temperature, though they are increasing with temperature. At the same Temperature of air, $\mathrm{D}_{\text {Surface }}<\mathrm{D}_{\text {Knudson }}<\mathrm{D}_{\text {Ordinary }}$, Diffusion coefficient (D) basically is analogous of heat transfer resistance in mass transfer. The all three diffusion coefficients, Surface diffusion coefficient is found to be minimum, nearly touching the abcissa, which shows that Surface diffusion mechanism dominates mass transfer inside silica gel particle.

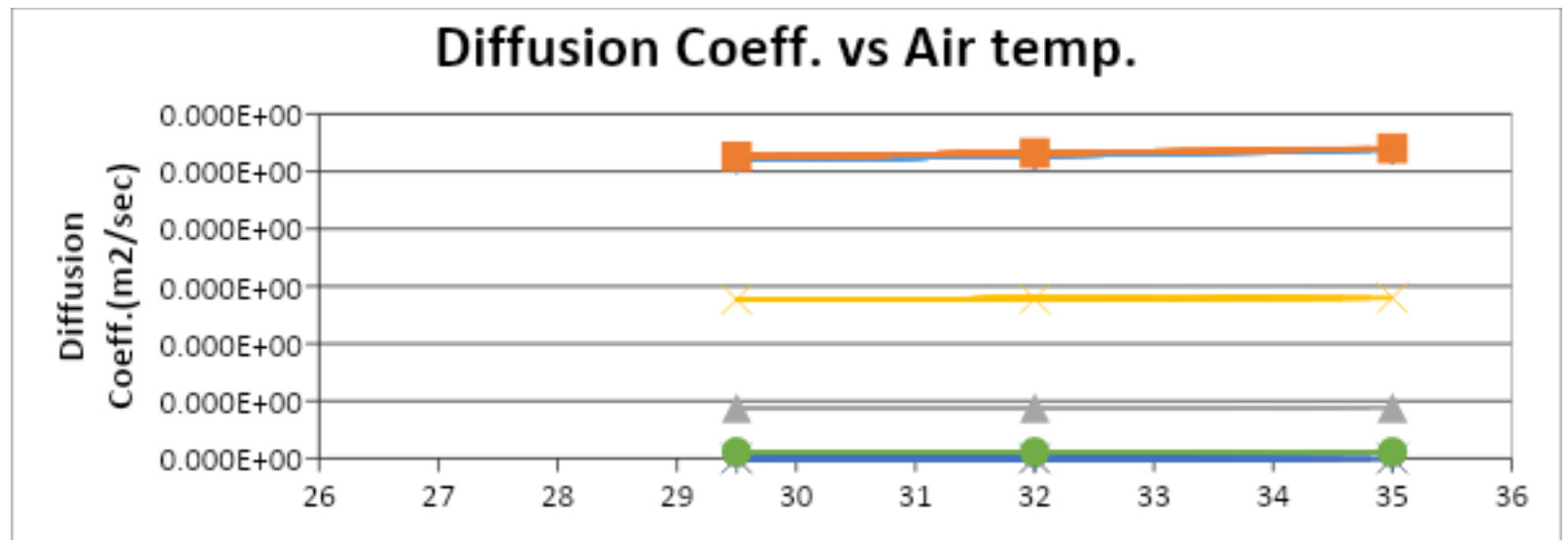


Figure 7. Comparison of Diffusion Coeff. b/w Packed bed (Pcb) vs Rotary Wheel (Rot)

In the figure 7, we have obtained 6 trends of variation (three trends from packed bed \& three trends from Rotary system). From this graph, it is clear that $\mathrm{D}_{\text {Surface }}<\mathrm{D}_{\text {Knudson }}<\mathrm{D}_{\text {Ordinary, }}$ this order confirms the fact that Surface diffusion dominates the mass transport phenomenon in Desiccant Dehumidification Analysis. Also it shows that $\mathrm{D}_{\text {SURFACE ROTARY }}<\mathrm{D}_{\text {SURFACE PACKED BeD }}<\mathrm{D}_{\text {KNUdSON }}$ ROTARY $<D_{\text {KNUDSON PACKED BED }}<D_{\text {ORDINARY ROTARY }}<D_{\text {ORDINARY PACKED BED. }}$ It also shows that Surface diffusion coefficient is found to be minimum in case of Rotary desiccant system, which implies that Moisture transport phenomenon dominates in case of Rotary desiccant system.

\section{CONCLUSIONS}

After completing this Heat Transfer Analysis on Silica gel, we came to infer that in between Pseudo Gas Controlled model and Solid Side Resistance model. Solid side Resistance model is better model to carry out the dehumidification analysis of Solid packed bed system.

After performing the mass transfer analysis on Silica gel, we came to conclude that Surface Diffusion is much effective mechanism of moisture transport for both Packed Bed system \& Rotary Desiccant Wheel system. And in between Rotary Desiccant System and Packed Bed System the Surface diffusion is found to be dominant in case of Rotary Desiccant System which is under continuous operation.

In a nutshell this complete process of heat and moisture Transfer between Silica gel and moist air can be understood as Heating with dehumidification in terms of psychrometry. Higher heat transfer coefficient and smaller diffusion coefficient, more efficient will be the process of Heating and dehumidification.

\section{REFERENCES}

[1] Xing, H. Y.H. (2000). Desiccant dehumidification analysis (Doctoral dissertation, Massachusetts Institute of Technology).

[2] Eileen Elisabeth Chant. (1991).Transient and Steady State Simulations of an Advanced Desiccant Enhanced Cooling Cycle, Ph.D. Thesis, Georgia Institute of Technology. 
[3] Pesaran, A.A. (1983). Moisture Transport in Silica Gel Particle Beds, Ph.D. Thesis, University of California, Los Angeles.

[4] Elsayed, M. M., \& Chamkha, A. J. (1997). Analysis and performance of radial flow rotary desiccant dehumidifiers.

[5] Abasi, S., Minaei, S., \& Khoshtaghaza, M. H. (2016). Performance of a recirculating dryer equipped with a desiccant wheel. Drying Technology, 34(8), 863-870.

[6] Dai, Y. J., Wang, R. Z., \& Zhang, H. F. (2001). Parameter analysis to improve rotary desiccant dehumidification using a mathematical model. International Journal of Thermal Sciences, 40(4), 400-408.

[7] Jani, D. B., Mishra, M., \& Sahoo, P. K. (2017). A critical review on solid desiccant-based hybrid cooling systems. International Journal of Air-conditioning and Refrigeration, 25(03), 1730002.

[8] Yaningsih, I., Wijayanta, A. T., Miyazaki, T., \& Koyama, S. (2018). Analysis of heat and mass transfer characteristics of desiccant dehumidifier system with honeycomb configuration. Applied Thermal Engineering, 144, 658-669.

[9] Hussain, T., Singh, A. K., Mittal, A., Verma, A., \& Alam, Z. (2020). Performance Evaluation of Vapor Compression Refrigeration System by Varying Air Flow Rates in Air-Cooled and Evaporatively Cooled Condensers. International Journal of Energy for a Clean Environment, 21(1).

[10] Hougen, O. A. (1947). Marshall, WR," Adsorption from a Fluid Stream Flowing through a Granular Bed. Chem. Eng. Prog, 43(4), 197-208.

[11] Ahlberg, J. E. (1939). Rates of water vapor adsorption from air by silica gel. Industrial \& Engineering Chemistry, 31(8), 988-992.

[12] Mills, A. F., Heat and Mass Transfer, Richard D. IRWIN, Inc., 1995.

[13] Edwards, D.K, et al., Transfer Processes, 2nd ed. Hemisphere/McGraw-Hill, New York, 1979.

[14] Sladek, K. J., Gilliland, E. R., \& Baddour, R. F. (1974). Diffusion on surfaces. II. Correlation of diffusivities of physically and chemically adsorbed species. Industrial \& Engineering Chemistry Fundamentals, 13(2), 100-105.

[15] San, J. Y., \& Jiang, G. D. (1994). Modeling and testing of a silica gel packed-bed system. International journal of heat and mass transfer, 37(8), 1173-1179. 
[16] Niu, J. L., \& Zhang, L. Z. (2002). Effects of wall thickness on the heat and moisture transfers in desiccant wheels for air dehumidification and enthalpy recovery. International Communications in Heat and Mass Transfer, 29(2), 255-268.

[17] Ge, T. S., Li, Y., Wang, R. Z., \& Dai, Y. J. (2008). A review of the mathematical models for predicting rotary desiccant wheel. Renewable and Sustainable Energy Reviews, 12(6), 1485-1528. 